\title{
USING WRITING ACROSS THE CURRICULUM (WAC) TECHNIQUES TO PROMOTE INCREASED STUDENT ENGAGEMENT AND LEARNING IN THE COMPUTER INFORMATION SYSTEMS CURRICULUM
}

\author{
Bruce Saulnier, Quinnipiac University, bruce.saulnier@quinnipiac.edu
}

\begin{abstract}
A case is made for the inclusion of writing in multiple places in the Computer Information Systems (CIS) curriculum to meet the expectations of industry for entry level employees. Writing across the Curriculum (WAC) principles are explained, and it is suggested that both Writing to Learn (WTL) and Writing in the Disciplines (WID) WAC pedagogical techniques are desirable for inclusion as part of the delivery of the CIS curriculum. Guidelines for the construction of WID assignments are presented. Examples of both WTL and WID are provided from the CIS curriculum at the Quinnipiac University. It is concluded that the use of both WTL and WID techniques in the CIS curriculum has served to both (1) increase student engagement both in and out of the classroom and (2) improve student writing and learning.
\end{abstract}

Keywords: Employer Expectations, Writing Across the Curriculum, Writing in the Discipline, Writing to Learn, Student Engagement, Student Learning.

\section{WRITING IN THE COMPUTER INFORMATION SYSTEMS CURRICULUM?}

"The act of putting pen to paper encourages pause for thought, this in turn makes us think more deeply about life, which helps us regain our equilibrium" - Norbet Platt

We live in an era of sound bites and 140 character messages, but good writing still matters when it comes to being successful in today's business environment. Paying attention to grammar, spelling and punctuation, along with good word choice and a consistent style, is important because bad writing can have a wide range of negative career and personal consequences.

As information systems professionals we use writing every day for a variety of purposes including to communicate information (memos, email, etc.), to clarify our thinking (when we work through an idea or problem in writing), to learn new concepts and information (taking notes on reading and research topics), and to write formal reports (requirements definition, feasibility study, systems proposals, etc.).

As aspiring professionals our students need practice to be able to use writing effectively to meet these same goals. One or two writing classes taken in the freshman year simply cannot provide enough daily practice to effectively increase the quality of our students thinking and writing. As one response to students' lack of writing practice throughout the university curriculum, Writing Across the Curriculum (WAC) programs began to emerge in the early 1980s. While the structure of individual WAC programs exhibit some degree of variation, the philosophies underlying these programs generally agree on certain basic principles:

- $\quad$ writing is the responsibility of the entire academic community;

- $\quad$ writing must be integrated across departmental boundaries;

- writing instruction must be continuous during all four years of undergraduate education;

- $\quad$ writing promotes learning; and

- only by practicing the conventions of an academic discipline will students begin to communicate effectively within that discipline.

Many recent studies of employer expectations of information systems graduates [11, 19] and curriculum requirements of IS professional organizations $[1,4,5,6,22]$ have reaffirmed the need to focus on improving the writing skills of our graduates. Including writing in courses has both short- and long-term benefits for both teachers and students. In the short term, teachers are better able to gauge how well students grasp information and where they need elaboration of key concepts. In the long run, as more CIS professors incorporate writing into more courses, 
students become more efficient at using writing as a communication and learning tool. Especially for more advanced or specialized work in the discipline, the professors reap the benefits of having students who are much better grounded in the fundamentals and ready to engage in more sophisticated analysis of ideas.

Like all language skills, writing skills atrophy when they aren't used. Yet our students often report that they do no writing at all during a semester because they don't even take notes during some classes. For students who take only multiple-choice exams, writing can be avoided almost completely for months at a time. Assigned writing in all courses helps students keep their writing skills sharp. Moreover, faculty in all disciplines have discovered that assigning writing in their classes helps students learn material and improve their thinking about major ideas in their courses. Writing assigned across the curriculum also helps students prepare for the day-in and day-out communication tasks they'll face on the job, no matter what their job is. Equally important, students need to learn about how writing is used within a discipline, and many kinds of assignments give students practice with disciplinary forms and conventions.

So why assign writing in your Information Systems classes? Students will learn more and will leave the university better prepared to face communication challenges if they write consistently over the course of a four-year college program. Specifically, students will learn more about the material in their courses if professors assign writing for their courses.

\section{WRITING TO LEARN (WTL)}

When considering how Writing across the Curriculum (WAC) has been implemented at a range of universities, the writing assignments generally fall into one of two categories - Writing to Learn (WTL) and Writing in the Disciplines (WID). While some teachers combine the two categories and assign writing that meets the goals of each, many teachers choose to focus on one type or the other.

Writing-to-learn (WTL) activities are short, impromptu or otherwise informal writing tasks that help students think through and/or discover key concepts or ideas presented in a course. Often, these writing tasks are limited to less than five minutes of class time or are assigned as brief, out-of-class assignments. Writing-to-learn (WTL) activities are considered to be crucial by many WAC programs because they can be used as evidence that students have learned the information and/or reveal/suggest areas in which there is an information deficit.

Although it is not clear exactly how writing fosters critical thinking [3], theoreticians and practitioners both agree that writing promotes both critical thinking and learning $[2,7,8,12,13,17,18]$. As Fulwiler and Young explain [10], "Writing to communicate--or what James Britton calls "transactional writing"--means writing to accomplish something, to inform, instruct, or persuade. . . Writing to learn is different. We write to ourselves as well as talk with others to objectify our perceptions of reality; the primary function of this "expressive" language is not to communicate, but to order and represent experience to our own understanding. In this sense language provides us with a unique way of knowing and becomes a tool for discovering, for shaping meaning, and for reaching understanding."

Forsman [9] makes the same point, but she directs her attention not to a theoretical justification but to a practical rationale for writing to learn. Forsman states, "As teachers we can choose between (a) sentencing students to thoughtless mechanical operations and (b) facilitating their ability to think. If students' readiness for more involved thought processes is bypassed in favor of jamming more facts and figures into their heads, they will stagnate at the lower levels of thinking. But if students are encouraged to try a variety of thought processes in classes, they can, regardless of their ages, develop considerable mental power. Writing is one of the most effective ways to develop thinking."

Writing to Learn (WTL) activities can happen frequently or infrequently in a class. Some can extend over the entire semester, and some can be extended to include a wide variety of writing tasks in different formats and to different audiences. Because they are examples of informal writing and are often given impromptu, WTL activities usually aren't marked for correctness. Rather, teachers or classmates quickly read the writing for a general sense of what students understand and what they don't understand. 
Writing-to-learn (WTL) activities take very little class time, and most teachers find they can give a quick WTL prompt at the beginning of class while they take roll and as students are settling in. Moreover, many WTL activities can be limited to just a minute or two - the amount of time it might take to answer a student's question about a course concept. Given that WTL activities are generally recognized to be very valuable student learning tools, most teachers feel that any minutes given over to WTL writing are very effective use of student time.

\section{WRITING TO LEARN IN THE CIS CURRICULUM}

\section{Writing to Learn in the Flipped Classroom Approach}

Writing to Learn prompts are used in the CIS curriculum as part of the author's "flipped classroom" approach to the Systems Analysis \& Design course. While different authors appear to espouse different key flipped classroom components, essential components common to all interpretations of the flipped classroom include the following:

- Provide an Opportunity for Students to gain First Exposure Prior to Class.

The mechanism used for first exposure can vary, from simple textbook or online readings to lecture videos to podcasts or screencasts. Videos can be created by the course instructor, or found online from sources such as YouTube, the Kahn Academy, MIT's OpenCourseWare, or other similar sources. The pre-class exposure does not need to be high-tech; students can be asked to simply complete pre-class reading assignments and/or engage in writing-to-learn exercises.

- Provide an Incentive for Students to Prepare for Class.

In all cases, students should be required to complete a task associated with their preparation, and that task should be associated with some points or percentage toward their final course grade. The assignment itself can vary, ranging from online quizzes to worksheets to short writing-to-learn assignments. In each case the task should provide an incentive for students to come to class prepared by speaking the common language of undergraduates: points. In many cases grading for completion rather than effort may be sufficient, particularly if in-class activities will provide students with the kind of feedback that grading for accuracy usually provides.

- Provide a Mechanism to Assess Student Understanding.

The pre-class assignments that students complete as evidence of their preparation can also help both the instructor and the student assess understanding. Pre-class quizzes can also allow the instructor to practice Just-in-Time Teaching [16], which means that the instructor can tailor class activities to focus on the elements with which students are struggling. If automatically graded, the quizzes can also help students pinpoint areas where they need help. Pre-class worksheets also can help focus student attention on areas with which they are struggling, and can serve as a departure point for in-class activities, while pre-class writing assignments can help students clarify their thinking about a subject, thereby providing for richer inclass discussions. Most importantly, the use of pre-class activities provides for the time needed to supply students with much needed feedback in class, reducing the need for instructors to provide extensive commentary outside of class [24]. Additionally, many of the activities used during class time (e.g., clicker questions, debates, etc.) can serve as informal checks of student learning.

- Provide In-Class Activities that Focus on Higher Level Cognitive Activities.

Given that the students have gained basic knowledge outside of class, class time can now be spent promoting deeper learning. The in-class activity selected will be dependent upon both the learning goals of the course and the culture of the discipline. For example, Lage [14] describes experiments students did in class to illustrate economic principles, while Mazur [15] focuses on student discussion of conceptual "clicker" questions and quantitative problems which focused on physical science principles. Other in class activities may consist of debates, data analysis, or synthesis activities. What is important, regardless of the activity chosen, is that students are using class time to deepen their understanding and increase their skills at using their newly acquired knowledge.

\section{Writing to Learn in the Systems Analysis \& Design (SAD) Course}

The use of WTL prompts as part of the flipped classroom approach for the SAD course was first implemented in the fall of 2013, and is currently in its third iteration. The course consists of an opening unit which concludes with 
students being assigned to project teams, after which the teams are assigned to improve a particular system/application in either the on campus or off campus environments.

The typical daily classroom unit consists of the following pattern:

- Students receive a Research Question (WTL prompt) at the close of the prior class;

- Students post their individual answers to the Research Question to the Blackboard course management system no later than midnight of the evening prior to the class session in which the topic will be covered;

- The class session opens with either an additional WTL prompt followed by a 10-15 minute comparison of the student answers to the Research Question, or just the 10-15 minute comparison of student answers. During the 10-15 minute session students search for commonalities in their answers, following which the students collectively decide which information to archive for summative assessment at a later date;

- Students then apply their understanding of the answers to their particular system or application.

For example, applying the pattern to the SAD class session covering System Requirements:

- Student Research Question: What are system requirements? What is the difference between functional system requirements and non-functional system requirements?

- In class, after the opening discussion, student project teams work together to define the functional and nonfunctional system requirements for their system or application.

- Project teams quickly come to realize that they cannot accurately define their requirements without input from the system stakeholders (a topic that was covered 2 weeks earlier in the course).

- Students are then provided with their research question and/or assignment that is due prior to the next class session. In particular, students are asked to find commonly employed techniques to gather data and to determine which data gathering technique(s) would be most appropriate to collect data from each class of stakeholder, which provides input for the following class session which covers Data Gathering Techniques.

Student postings to the course management system are usually graded on a 2-point scale with $0=$ answer not submitted by the deadline; 1 = standard Wikipedia answer and/or grammatical errors in the submission; $2=$ grammatically correct and additional source(s) used to provide their answer. No late postings are accepted because all research assignments are posted to the course management system well in advance of the required due dates.

At the close of each class session, students and faculty together decide which information would be best archived for those students who missed class due to illness or other higher priority interventions. This archived material becomes the basis for the construction of individual summative assessments that provide for individual accountability in what is predominantly a team-based course producing team-based project deliverables.

It is important to note that the flipped classroom approach employed herein is not merely a synonym for either viewing online videos or searching for information on the internet. In fact, it is the in-class interactions and carefully designed meaningful learning activities that occur during the classroom face-to-face time that are the most important part of the flipped classroom. Students do not work without structure in class, nor do they work in isolation, nor do they spend the entire class time staring at a computer screen. Rather, the flipped classroom is an opportunity to increase intentionally designed and meaningful interactions between students and faculty.

\section{WRITING IN THE DISCIPLINES (WID)}

The second category of WAC is often called Writing in the Disciplines (WID). Writing assignments of this sort are designed to introduce or give students practice with the language conventions of a discipline as well as with specific formats typical of a given discipline. For example, a feasibility study would include much different information in a unique format that would differ greatly from an annual business report or an engineering lab report.

WID assignments are typically, but not exclusively, formal documents prepared over a few weeks or even months. The final documents adhere to the format and style guidelines of project deliverables typical of the professional genres they are helping students learn about. Teachers comment primarily on the substance of these assignments, but teachers also expect students to meet professional standards of layout and proofreading (format and mechanical correctness). 
Although the research essay is the most common kind of WID assignment, it's not the only format that students can use to learn about disciplinary writing conventions. For example, in the typical Systems Analysis \& Design course students would produce the following types of documents to understand the thinking and writing of the systems development process: (1) a record of the initial client meeting(s); (2) a systems requirements document; (3) a feasibility study; etc.

In addition to discipline-specific formats, other kinds of writing assignments can help students learn the language and ways of thinking of a discipline, even though they may not mimic its professional writing. Any of these writing activities can provide the basis for a longer, more formal assignment, or can be used only to promote class discussion and/or thinking about course material:

- Reading journal - jotting down specific thoughts regarding an assigned reading

- Jargon/term journal - jotting down terms and their meanings when confronted with new discipline specific terminology

- Rhetorical analysis - reading an article and analyzing its meaning; for example, a mini-case study emphasizing an important point

- Popular article - for example, our students do a "Tech Week in Review" single-page analysis of tech happenings on a weekly basis in our introductory course

One reason that students report feeling overwhelmed by WID tasks is that they aren't sure where to start and then how to proceed to produce a good project of the sort required by the assignment. You can help students--and get better final drafts to read--by setting up a sequence of tasks that build toward the final project. Two approaches work well when designing a sequence:

1. Break the large writing task into chunks so that students can tackle parts of the assignment and get feedback before moving to the next chunk.

2. An alternative is to devise tasks that build on each other. For instance, if you hope to assign a professional review of literature as the final project, first have students write abstracts or summaries of articles, then ask for annotations, and finally ask for synthesis. At the same time, have students analyze published articles to determine what a review of literature typically looks like in your field. By giving students a sequence of writing and analytic tasks, they become more confident and more able to meet your criteria for the final writing task.

If you decide to give a disciplinary writing assignment (a formal document that students work on over a long period and revise before submitting it for grading), then peer review is an excellent way to assure that students are revising. One way to save class time is to require students to do their peer review as homework outside of class. They will appreciate having class time for peer review, but you can either require that they meet to read, comment on, and discuss each other's draft or that they exchange drafts at the end of one class and return drafts and peer review sheets at the beginning of the next class. If you decide to require out-of-class peer review, you might want students to contact each other and exchange drafts through e-mail.

\section{GUIDELINES FOR SUCCESSFUL WID ASSIGNMENTS}

Successful writing assignments depend on careful and thorough instructions and preparation and on explicit criteria for evaluation. Although individual experience with a given assignment will suggest ways of improving the assignment, following explicit guidelines in initial assignment construction serves to assist in avoiding potential problems with student writing and thus makes for both better writing and thereby considerably reduced grading time.

Surprisingly, many teachers have been known to assign writing tasks without articulating to themselves what the task is supposed to do for students. Good writing assignments always start with a clear goal that the teacher can express, one that is usually included on the assignment sheet so that students also understand the goal of the assignment. 
Working backwards from what the course instructor hopes the final drafts will look like often produces the best assignments. In particular, consideration of the following questions might provide useful guidance in constructing assignment particulars:

- Why should students write in the class? State the goals for the final written product as clearly and concretely as possible by tying the writing to specific pedagogical goals of the course.

- Determine which particular writing products will both meet the pedagogical goals and align with the course instructor's individual teaching style/preferences.

- Sequence course activities (reading, researching, and writing) to build toward the final product.

Good writing assignments also often take shape by thinking backwards; in effect, teachers ask themselves, "What do I want to read at the end of this assignment?" By working from what they anticipate the final product should look like, teachers can give students detailed guidelines about both the writing task and the final written product by including information such as the following on the assignment sheet:

- Rhetorical aspects of the task; i.e.., audience, purpose, and writing situation

- Required sections/elements of the writing assignment

- Breaking down the writing task into a manageable sequence of steps

- Grading criteria

\section{WID IN THE COMPUTER INFORMATION SYSTEMS CURRICULUM}

Discipline based writing assignments are present in almost all required CIS courses at Quinnipiac University. The following is a partial listing of WID assignments in the required major courses.

\section{Introduction to Information Systems}

The Introduction to Information Systems course includes two distinct writing to learn activities: "Tech Week in Review" journal entries and a final exam take-home portion which is a Reflection Paper in which the individual student's focus on their learning from using the SDLC to develop an iPhone application.

\section{Systems Analysis \& Design}

The Systems Analysis \& Design (SAD) course involves project teams doing an analysis and redesign of a real world information system. Project teams do several WID activities including developing a Team Charter and producing several deliverables involved in the first three stages of the Systems Development Life Cycle (SDLC). Specific WID assignments treated as project deliverables in the SAD course include: (1) a summary report of the initial client meeting; (2) a problem definition statement; (3) a system scope statement; (4) a system request; (5) a feasibility analysis; (6) a requirements definition report; (6) a system specification; and (7) a system proposal.

\section{Enterprise Systems}

The Enterprise Systems course explores the design, selection, implementation, and management of enterprise IT solutions. The first half of the course deploys several case studies to explore enterprise systems concepts and requires formal case write-ups. During the second half of the course, SAP simulations are employed and student teams are required to provide user documentation for a particular SAP system.

\section{Database Programming \& Design}

The Database Programming and Design course presents the use of database architecture and programming as a tool for developing integrated solutions for the information requirements of a modern business environment. Student teams produce a Group Consulting Report that analyzes and provides examples of the data needs of an organization, including business requirements definition, data needs to support the business requirements, a data model based on the data needs, physical implementation of the proposed data model, and samples queries to support the data model. 


\section{IT Project Management}

The IT Project Management course focuses on the processes, methods, techniques, and tools that organizations use to manage their information systems projects. Students produce a Project Charter, a Team Contract/Charter, a Work Breakdown Structure, a Project Schedule/Gantt Chart, and weekly project status reports. Additionally, they produce an Executive Summary as part of their final project deliverables.

\section{IT Internship}

The specific WID assignment associated with the IT Internship course is a Company Industry Report. The assignment is designed for the student to research the company the student will be working for, understand the market(s) in which the company competes, and how the company is currently performing within its defined target market(s). Students are required to research the company using the company's annual report, analysis from organizations such as Standard \& Poor's, etc. to find out about the company's financial performance, its strategic goals and objectives, its opportunities and threats, what is reported about the company on social media, and any other pertinent information available.

\section{RESULTS}

The use of WTL prompts both prior to and at the beginning of individual class sessions has effectively increased student engagement both outside of the classroom and inside the classroom. Students have increased their reading outside the classroom because they have read online material to answer particular research questions related to course content prior to encountering the content in their classes. As such, and because the students have available to them the content/answers that they submitted the evening prior to the class session, students are much more engaged in the content and classroom discussions are much more lively.

As students have written more via both WTL and WID assignments, student learning has increased in both the individual courses and throughout the curriculum. Though longitudinal studies are nearly impossible to conduct due to the absence of a control group, individual student writing has exhibited great improvement over the course of their four-year undergraduate experience. The presence of WTL assignments which increase student engagement in the course content both in and out of the classroom, coupled with the use of WID assignments in successive courses which have greatly increased the individual student's writing ability, have effectively produced undergraduates whose writing skills and field-specific knowledge are much closer to being in alignment with employer expectations of our graduates.

\section{CONCLUSIONS}

To conclude, it is apparent that the use of WID assignments in successive CIS courses has both reinforced student's understanding of the need for effective professional writing and increased the quality of student writing as students have progressed through the curriculum. As student writing has improved via the constant reinforcement of writing assignments, students have learned to think at a higher level. As Zakaria [25] so effectively proffers, "The central virtue of a Liberal Education is that it teaches you how to write, and writing makes you think. Whatever you do in life, the ability to write clearly, cleanly, and reasonably quickly will prove to be an invaluable skill."

Although the results of the use of WAC techniques across the CIS curriculum have been very positive, this study is at best preliminary. Areas for future investigation include: (1) the relative influence of various forms of formative feedback on the increase of student writing effectiveness; (2) possible increase in student self-efficacy as both writers and learners vis-à-vis their increased writing proficiency; (3) the similarities/differences of results of employing these WAC techniques in on-line courses; and (4) the application of WID best practices to the construction of WID assignments in the CIS discipline. 


\section{REFERENCES}

1. ABET, Computing Accreditation Commission (CAC) (2013). Criteria for Accrediting Computing Programs, 2014-2015. Retrieved April 13, 2015 from http://www.abet.org/cac-criteria-2014-2015/

2. Adams, P. (Ed.) (1973). Language in Thinking. Harmondsworth: Penguin Press.

3. Applebee, A.N. (1985). Writing and Reasoning. Review of Educational Research, 54(4), 577-596.

4. Association of American Colleges \& Universities (AAC\&U) (2013). Liberal Education and America's Promise (LEAP). Retrieved April 13, 2015 from http://www.aacu.org/leap

5. Association to Advance Collegiate Schools of Business (AACSB) (2013). Eligibility Procedures and Accreditation Standards for Business Accreditation. Retrieved April 13, 2015 from http://www.aacsb.edu/en/accreditation/standards/2013-business.aspx

6. Attaway, A., Chandra, S., Dos Santos, B., Thatcher, M., \& Wright, A. (2011). An Approach to Meeting AACSB Assurance of Learning Standards in an IS Core Course. Journal of Information Systems Education, 22(4), 355-366.

7. Bruner, J. (1975). Language as an Instrument of Thought. In A. Davies (Ed.), Problems in language and learning. London: Heinemann.

8. Emig, J. ( 1977). Writing as a Mode of Learning. College Composition and Communication, 28, 122-28.

9. Forsman, S. (1985). Writing to Learn Means Learning to Think. In A. R. Gere (Ed.), Roots in the sawdust: Writing to learn across the disciplines (pp. 162-174). Urbana, IL: National Council of Teachers of English.

10. Fulwiler, T. \& Young, A. (1982). Introduction. In T. Fulwiler and A. Young (Eds.), Language connections: Writing and reading across the curriculum (pp. ix-xiii). Urbana, IL: National Council of Teachers of English.

11. Hart Research Associates (2013). It Takes More than a Major: Employer Priorities for College Learning and Student Success. Washington, DC: The Association of American Colleges and Universities.

12. Herrington, A. (1981). Writing to Learn: Writing Across the Disciplines. College English, 43, 379-87.

13. Knoblauch, C., \& Brannon, L. (1983). Writing as Learning through the Curriculum. College English, 45, 46574.

14. Lage, M., Platt, G. \& Treglia, M. (2000). Inverting the Classroom: A Gateway to Creating an Inclusive Learning Environment. Journal of Economic Education, 31:30-43.

15. Mazur, E. (2009). Farewell, Lecture? Science 323: 50-51.

16. Novak, G., Patterson, E., Gavrin, A., \& Christian, W. (1999). Just-in-Time Teaching: Blending Active Learning with Web Technology. Upper Saddle River, NJ: Prentice Hall.

17. Odell, L. (1980). The Process of Writing and the Process of Learning. College Composition and Communication, 36, 42-50.

18. Parker, R. P., \& Goodkin, V. (1987). The Consequences of Writing: Enhancing Learning in the Disciplines. Upper Montclair, NJ: Boynton/Cook.

19. Pratt, J., Keys, A., \& Wirkus, T. (2014). Preparing Information Systems Graduates for a Complex Society: Aligning IS Curricula with Liberal Education Learning Outcomes, Journal of Information Systems Education, 25(1), 35-44.

20. Russell, D. R. (1991). Writing in the Academic Disciplines, 1870-1990: A Curricular History. Carbondale: Southern Illinois University Press.

21. Saulnier, B. (2015). The Flipped Classroom in Systems Analysis \& Design: Leveraging Technology to Increase Student Engagement. Information Systems Education Journal, 13(4), 33-40.

22. Topi, H., Valacich, J., Wright, R., Kaiser, K., Nunamaker, Jr, J, Sipior, J., \& De Vreeda, G.-J. (2010). IS 2010: Curriculum Guidelines for Undergraduate Degree Programs in Information Systems. Communications of AIS, 26, 359-428.

23. Walvoord, B.E. 1992. Getting started. In Writing across the curriculum: A guide to developing programs, edited by S.H. McLeod and M. Soven. Newbury Park, CA: Sage.

24. Walvoord, B. \& Anderson, V. (1998). Effective Grading: A Tool for Learning and Assessment. San Francisco: Jossey-Bass.

25. Zakaria, F. (2015). In Defense of a Liberal Education. New York: W. W. Norton. 